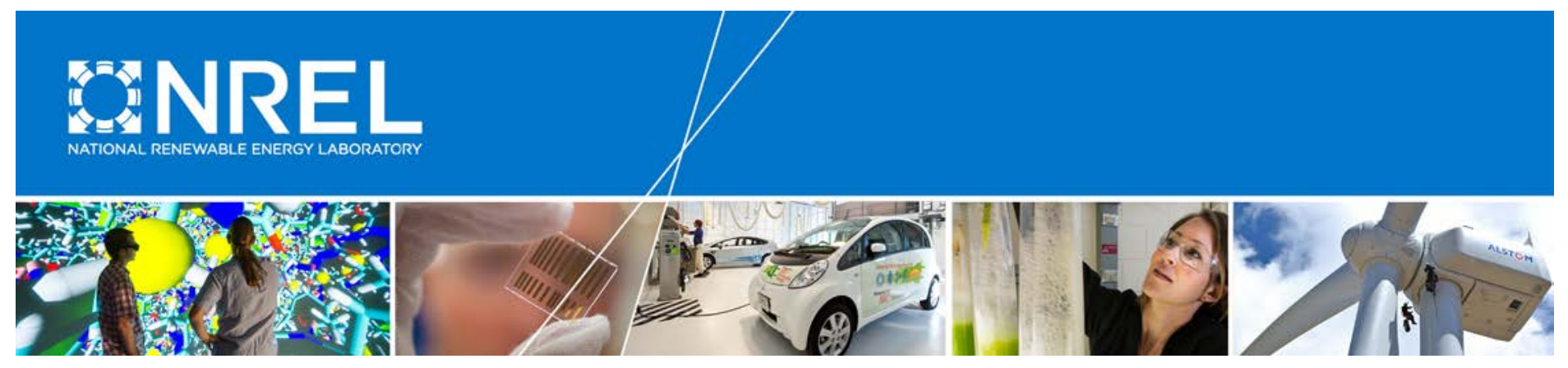

\title{
Decreasing Soft Costs for Solar Photovoltaics by Improving the Interconnection Process: A Case Study of Pacific Gas and Electric
}

Kristen Ardani and Robert Margolis National Renewable Energy Laboratory

NREL is a national laboratory of the U.S. Department of Energy Office of Energy Efficiency \& Renewable Energy Operated by the Alliance for Sustainable Energy, LLC

This report is available at no cost from the National Renewable Energy Laboratory (NREL) at www.nrel.gov/publications.

Technical Report

NREL/TP-7A40-65066

September 2015 


\section{Decreasing Soft Costs for Solar Photovoltaics by} Improving the Interconnection Process:

\section{A Case Study of Pacific Gas and Electric}

Kristen Ardani and Robert Margolis

National Renewable Energy Laboratory

Prepared under Task No. SM13.0532

NREL is a national laboratory of the U.S. Department of Energy Office of Energy Efficiency \& Renewable Energy Operated by the Alliance for Sustainable Energy, LLC

This report is available at no cost from the National Renewable Energy Laboratory (NREL) at www.nrel.gov/publications.

National Renewable Energy Laboratory 15013 Denver West Parkway Golden, CO 80401

303-275-3000 • www.nrel.gov
Technical Report

NREL/TP-7A40-65066

September 2015

Contract No. DE-AC36-08G028308 


\title{
NOTICE
}

This report was prepared as an account of work sponsored by an agency of the United States government. Neither the United States government nor any agency thereof, nor any of their employees, makes any warranty, express or implied, or assumes any legal liability or responsibility for the accuracy, completeness, or usefulness of any information, apparatus, product, or process disclosed, or represents that its use would not infringe privately owned rights. Reference herein to any specific commercial product, process, or service by trade name, trademark, manufacturer, or otherwise does not necessarily constitute or imply its endorsement, recommendation, or favoring by the United States government or any agency thereof. The views and opinions of authors expressed herein do not necessarily state or reflect those of the United States government or any agency thereof.

This report is available at no cost from the National Renewable Energy Laboratory (NREL) at www.nrel.gov/publications.

Available electronically at SciTech Connect http:/www.osti.gov/scitech

Available for a processing fee to U.S. Department of Energy and its contractors, in paper, from:

\author{
U.S. Department of Energy \\ Office of Scientific and Technical Information \\ P.O. Box 62 \\ Oak Ridge, TN 37831-0062 \\ OSTI http://www.osti.gov \\ Phone: 865.576.8401 \\ Fax: 865.576.5728 \\ Email: reports@osti.gov
}

Available for sale to the public, in paper, from:

\author{
U.S. Department of Commerce \\ National Technical Information Service \\ 5301 Shawnee Road \\ Alexandria, VA 22312 \\ NTIS http://www.ntis.gov \\ Phone: 800.553 .6847 or 703.605 .6000 \\ Fax: 703.605.6900 \\ Email: orders@ntis.gov
}




\section{Acknowledgments}

The authors would like to thank the following individuals from Pacific Gas and Electric (PG\&E) for their contributions to and review of this work: Robert Chan, Greg Disse, Simone Elberti, Dave Gabbard, Aily Ma, Nadim Virani, and Justine Yu. In particular, we would like to thank Bob Woerner for sharing his expertise and providing us the opportunity to meet with, and interview, PG\&E's Electric Generation Interconnection team. We would also like to thank Emerson Reiter (National Renewable Energy Laboratory) and Jarrett Zuboy (Consultant). This work was supported by the U.S. Department of Energy SunShot Initiative under contract number DE-AC36-08GO28308. 


\section{List of Acronyms}

ACE-IT Application Configuration and Eligibility Interconnection Tool

AHJ authority having jurisdiction

CAISO California Independent System Operator

CPUC California Public Utilities Commission

CRM customer relations management

DG PV distributed-generation photovoltaic

EAS enterprise application software

EGI team Electric Generation Interconnection team

FERC Federal Energy Regulatory Commission

FERC-WDT Wholesale Distribution Tariff

PG\&E Pacific Gas and Electric

PTO permission to operate

SNEM standard net energy metered 


\section{Table of Contents}

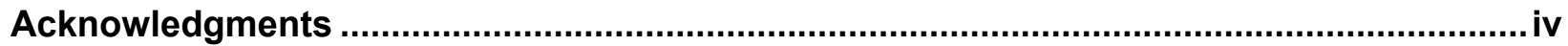

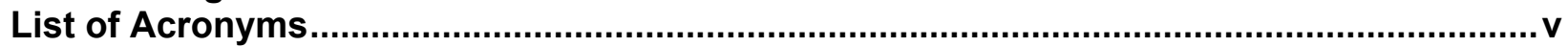

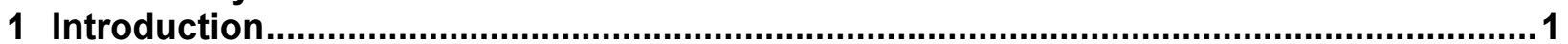

2 Interconnection Work Streams and Overview of Improvements ................................... 2

$2.1 \quad$ Wholesale and CA Rule 21 Interconnection Improvements .................................................... 3

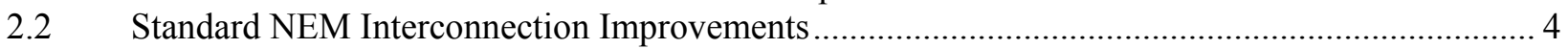

3 Benefits of Interconnection Process Improvements for Standard NEM ........................ 7

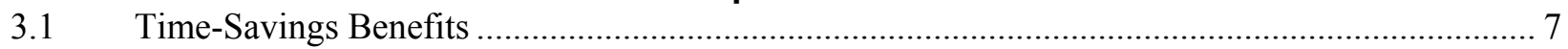

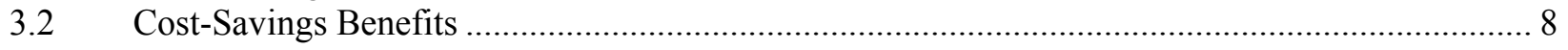

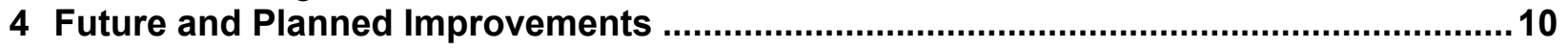

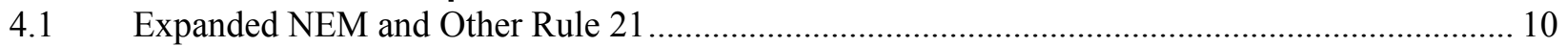

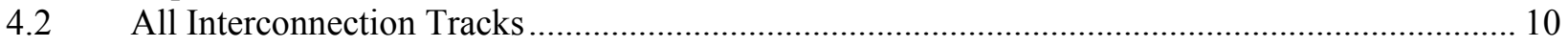

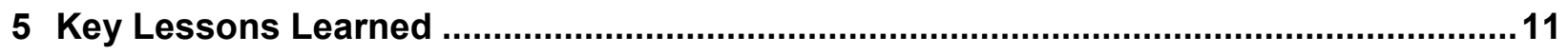

\section{List of Figures}

Figure 1: California Interconnection Tracks and PG\&E EGI Team's Work Streams .............................. 2

Figure 2: PG\&E Standard Net Energy Metering Interconnections 2001-2015 (Dashed Indicates

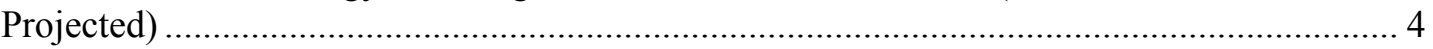

Figure 3: Architecture for PG\&E Standard NEM Process Streamlining and Automation ......................... 6

Figure 4: PG\&E Standard NEM Cycle Time Quartiles ....................................................................... 8

Figure 5: Annual Cost Savings from Standard NEM Process Improvements ......................................... 9

\section{List of Tables}

Table 1: PG\&E Average Processing Cost per Standard NEM Interconnection Application. 


\section{Abstract}

As of the end of 2014, Pacific Gas and Electric (PG\&E) had connected over 130,000 DG PV systems in its service territory, more than any other utility in the U.S. In this case study, we examine how PG\&E achieved a faster, more efficient interconnection approval process despite rising application volumes. Our goal is to draw insights from PG\&E's experience that can help to inform decision making at other utilities across the U.S. that may face similar trajectories for DG PV market growth. 


\section{Introduction}

In states with active distributed-generation photovoltaic (DG PV) markets, as the volume of DG $\mathrm{PV}$ grows, utilities typically face increasing pressure to keep pace with interconnection requests. From the electric utility's perspective, the rapid rise in DG PV interconnection applications can create workflow challenges, increase the expense of application processing, and slow turnaround times for issuing permission to operate (PTO) and final authorization for interconnection. These emerging challenges can interfere with utility strategic planning efforts and erode customer relations. In response to the deficiencies of typical interconnection application processes, utilities are beginning to implement innovative approaches to streamline inefficient procedures, improve communication with customers, and reduce costs internally as well as those incurred by PV developers.

As of the end of 2014, Pacific Gas and Electric (PG\&E) had connected over 130,000 DG PV systems in its service territory, more than any other utility in the U.S. With annual interconnections increasing an order of magnitude over the past decade (from about 4,000 in 2004 to about 40,000 in 2014), PG\&E implemented a suite of streamlining and automation measures that resulted in a reduction in application approval time frames.

In this case study, we examine how PG\&E achieved a faster, more efficient interconnection approval process despite rising application volumes. Our goal is to draw insights from PG\&E's experience that can help to inform decision making at other utilities across the U.S. that may face similar trajectories for DG PV market growth.

Section 2 discusses PG\&Es organization of its interconnection process into three work streams and the chronology of innovations undertaken by PG\&E to date to improve the interconnection processes for two of its work streams: exporting PV systems and standard net energy metered (SNEM) PV systems. Section 3 quantifies the time- and cost-savings benefits of PG\&E's improved interconnection process specifically for SNEM systems. Section 4 describes future and planned improvements to PG\&E's interconnection processes, and Section 5 provides key lessons learned and conclusions. 


\section{Interconnection Work Streams and Overview of Improvements}

PG\&E's Electric Generation Interconnection (EGI) team evaluates and processes all new applications for interconnection within PG\&E's service territory. Interconnection applications fall into three separate PG\&E work streams based on system size and whether power is exported to the utility grid: 1) Standard NEM systems (solar PV and wind up to $30 \mathrm{~kW}$ ), 2) Expanded NEM (solar PV and wind from $30 \mathrm{~kW}$ to $1 \mathrm{MW}$ ) and Other Rule $21^{1}$, and 3) Systems that export power for sale. The highest volume of applications falls under SNEM. The most complex work stream - in terms of types of systems, paperwork, tracking, and jurisdictional requirements - is for power-exporting PV systems. In this work stream, two wholesale interconnection tracks fall under Federal Energy Regulatory Commission (FERC) jurisdiction: the Wholesale Distribution Tariff (FERC-WDT), typically $150 \mathrm{~kW}$ and greater; and the transmission-level export via California Independent System Operator (CAISO), typically $5 \mathrm{MW}$ and greater. In addition, nonwholesale interconnections in this work stream are subject to California Public Utilities Commission (CPUC) jurisdiction under Rule 21 (typically $150 \mathrm{~kW}$ and greater). Figure 1 depicts the interconnection tracks in California as well as PG\&E EGI team's three work streams.

\section{Electric Generation Interconnection (EGI) Scope}

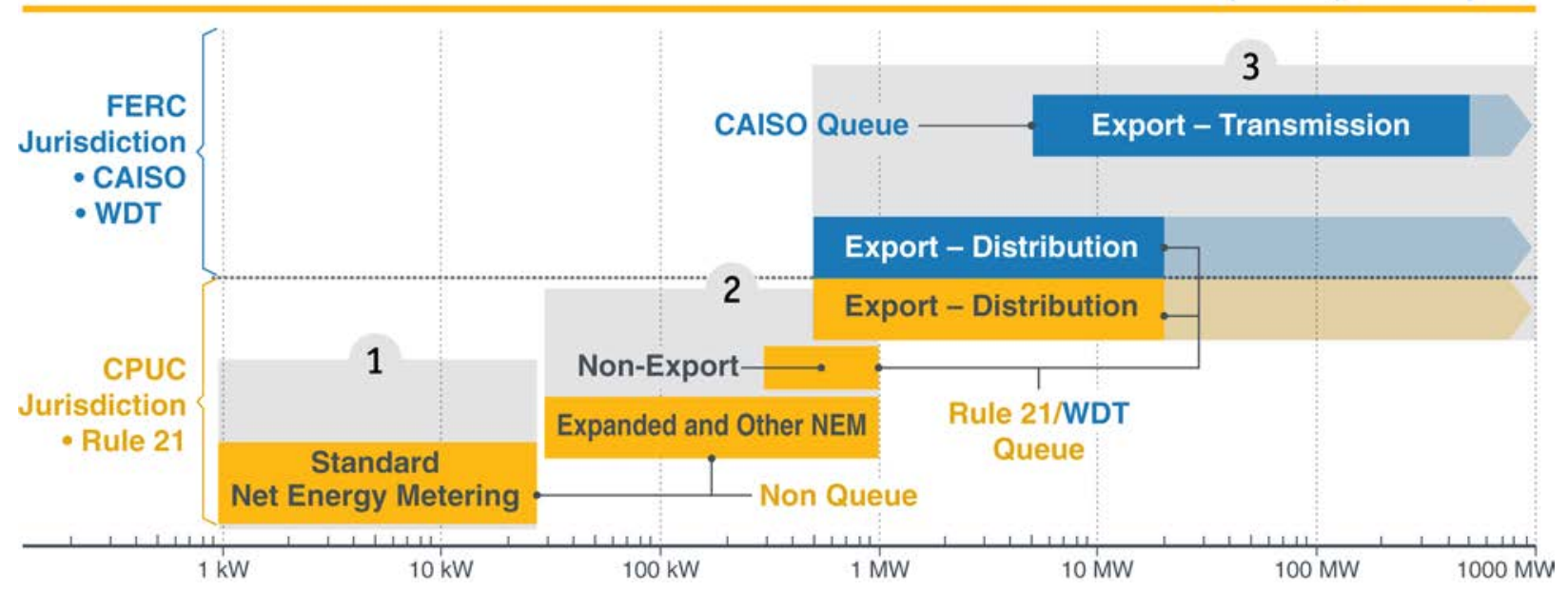

Figure 1: California Interconnection Tracks and PG\&E EGI Team's Work Streams

\footnotetext{
1 "Electric Rule 21 is a tariff (or set of regulations) that describes the interconnection, operation and metering requirements for distributed generators to be connected to a utility's electric system. The California Public Utilities Commission (CPUC) has jurisdiction over the Electric Rule 21 tariff. The Rule 21 tariff and the related CPUCapproved interconnection agreements are generally the same for each of California's large investor-owned utilities (PG\&E, San Diego Gas \& Electric Company and Southern California Edison)." (source: Pacific Gas and Electric)
} 


\subsection{Wholesale and CA Rule 21 Interconnection Improvements}

In mid-2012, PG\&E conducted an internal assessment of its end-toend interconnection process for wholesale projects and identified several opportunities to improve operations and implement efficiency gains. Based on the findings of this assessment, by the end of 2012, the utility had begun to implement a series of measures focused on automating the interconnection process, improving work-flow management, and ensuring compliance with FERC technical and time-frame requirements. In addition to this effort, PG\&E introduced streamlining measures for interconnections subject to CPUC jurisdiction under Rule 21. Among PG\&E's most impactful changes was the adoption of enterprise application software (EAS) to integrate and consolidate the internal management and processing of FERC WDT, CAISO transmission, and CA export Rule 21 interconnections. Generally, EAS enables various departments within a company to interact with a common corporate database for a wide range of applications. In the case of PG\&E, embracing an enterprise planning approach greatly improved the work-flow management across the varying interconnection tracks for PV systems that export power and also enhanced PG\&E's ability to respond to customer inquiries.

Later, in 2013, the utility tied the EAS workflow capabilities to an online portal for application submission and also adopted an enhanced customer relations management (CRM) system for tracking e-mail communications with PV installers. Most communication between PV installers and the utility regarding application status and approval is handled via email; therefore, it is imperative for the utility to retain and track records of email communication in order to demonstrate compliance with FERC and CPUC interconnection time-frame mandates. Prior to adopting the CRM system, PG\&E would manually save copies of customer e-mail communication to a SharePoint site for document retention and retrieval. This manual method was very time consuming for PG\&E staff. In contrast, the CRM system automated e-mail tagging and document retention, and it proved to be a significant time-savings measure. Another key feature driving the successful implementation of the CRM system was its compatibility with the existing PG\&E network, as well as its ease in interfacing with both EAS and PG\&E's e-mail server. By interfacing the CRM system with the EAS, the EGI team arrived at an integrated solution across numerous back-end processes resulting in the following: manageable workloads with reduced staff headcount, robust queue assignment, improved task management with realtime reporting, simplified document retention and retrieval of compliance records, and faster cycle times than tariff requirements. 


\subsection{Standard NEM Interconnection Improvements}

Late in 2012, shortly after beginning to implement the improvements for FERC wholesale and CA Rule 21 interconnection applications, the utility undertook a multi-year overhaul of its interconnection process for SNEM applications. Recognizing the need to simplify the entire process in the face of rising SNEM volumes (see Figure 2), PG\&E first eliminated unnecessary application requirements, such as providing proof of 24/7 access to the meter and conducting a detailed insurance review.

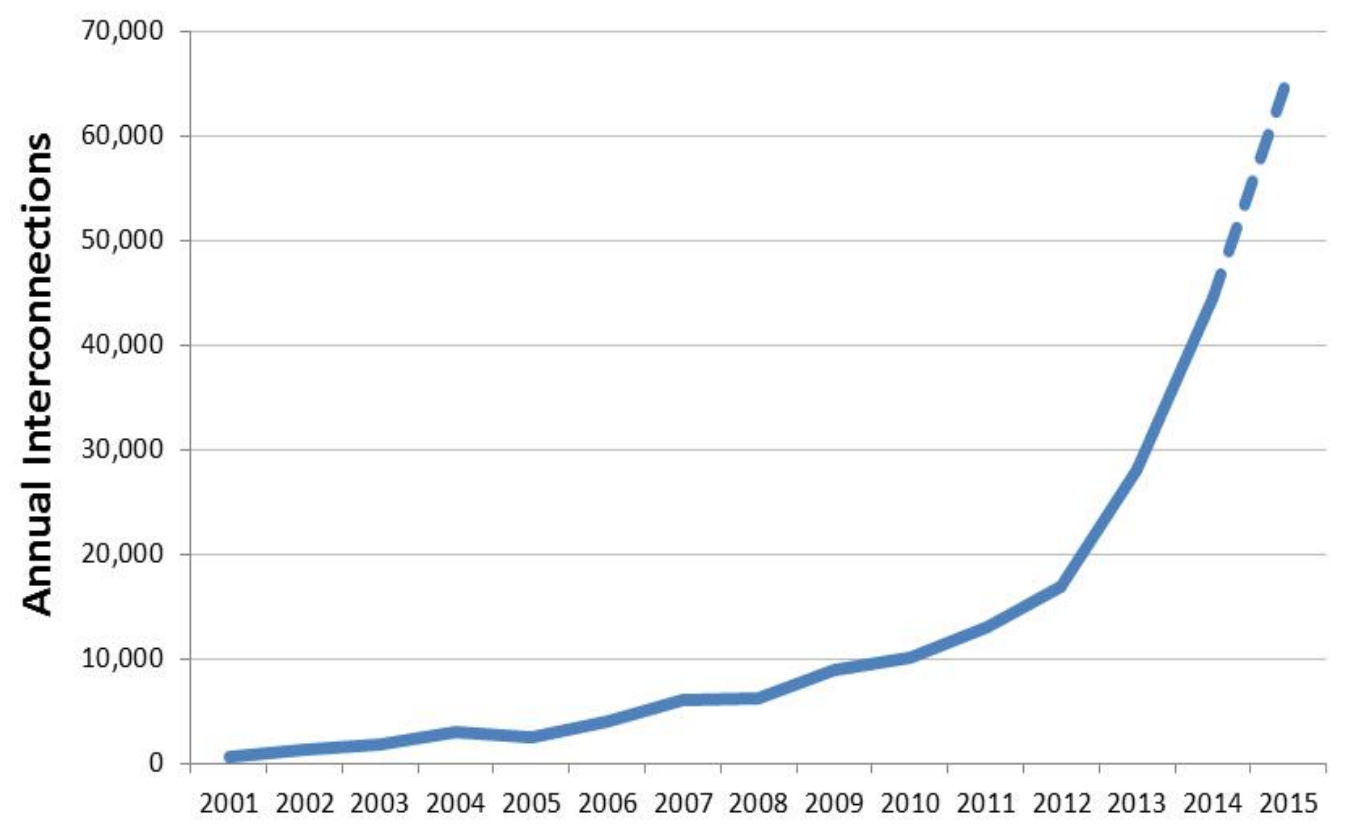

Figure 2: PG\&E Standard Net Energy Metering Interconnections 2001-2015 (Dashed Indicates Projected)

After eliminating unnecessary requirements, PG\&E focused on measures to streamline the process and then to automate it. Figure 2 depicts the rapidly rising volumes of SNEM PV systems in PG\&E's territory-from 584 annual interconnections in 2001 to a projected 70,000 by the end of 2015 .

One of the changes that dramatically reduced PG\&E's application processing time is the adoption of online application completion and submission, which was piloted near the end of 2014. Prior to adopting the online system, there was no single point of entry for new SNEM applications, and it became difficult for PG\&E to track applications received through multiple channels such as mail, fax, and e-mail. Moving to an online system has multiple benefits, such as enabling the EGI team to easily identify when an application was received and processed, decreasing application re-work via built-in error checking and auto-population of key information, and improving access to the California Energy Commission's certified equipment list via integration with the Go Solar website.

The capability to auto-populate key application inputs - such as customer information and eligible rate schedules, along with built-in data validation and tool tips-has proven particularly effective in reducing the time and cost of application processing because it saves customers' time 
when completing applications and ensures a higher level of accuracy. Further, the online system contains templates for response e-mails from the utility indicating the application status such as whether a project needs further study, failed the study, or is approved. By moving to automated, template-based e-mails, the EGI team has reduced the amount of staff time spent drafting customer responses and has accelerated the utility's response rate. Another key feature of the online application system is the provision of a basic single-line diagram template for use by installers. The installer simply checks a box to indicate the basic single-line diagram instead of submitting a custom diagram. PG\&E also separated the application into two components: 1) Agreement and Customer Authorization that requires a signature and 2) Application with more technical details. The split allows for the legal document that requires a Customer signature to contain the minimum data set needed to jump-start the interconnection process. The application can then be processed independently, thus avoiding unnecessary delays. Also, the functionality of electronic signature was built into the online Agreement and Customer Authorization form, further expediting cycle times.

In addition to automating the application processing, PG\&E has also automated the initial engineering review for potential system-load impacts. This new, automated screening system relies on aggregating information from various sources, including equipment information and specifications provided via the online application portal, distribution-feeder information from PG\&E's asset management system, transformer location determined by meter identification number, and billing information. This aggregated information is tied to built-in calculations that are used to automatically complete required initial review screens, such as whether a proposed interconnection will exceed acceptable transformer loads. Achieving this level of automation relies on the integration of several back-end data streams that were previously isolated from one another and were in separate utility data management systems. After implementing the automation measures, EGI staff time is only needed now to verify that the building permit and agreement is signed and to manage exception cases where further study or distribution-grid upgrades are needed. Figure 3 depicts PG\&E's architecture for integrating various data streams and systems.

With respect to the final approval to energize a constructed PV system, PG\&E improved the PTO process by offering PV end-users the option to allow PG\&E to send the PTO notification directly to the PV system installer; this option obviates the need for the end-user to pass the utility communication to the installer. PG\&E also adopted automated and remote smart-meter programming, thus eliminating the need for an in-person physical meter swap or programming effort. 


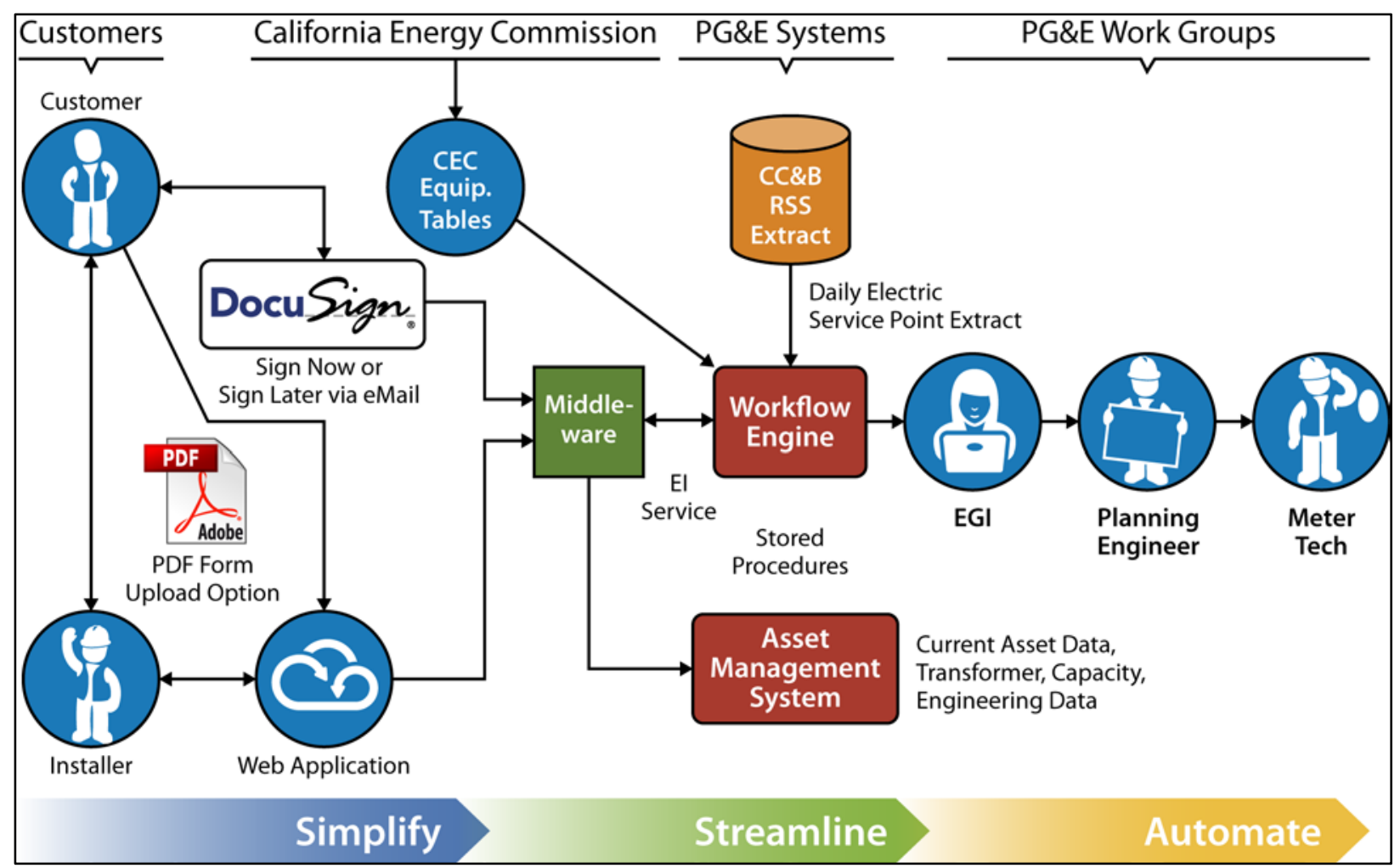

Figure 3: Architecture for PG\&E Standard NEM Process Streamlining and Automation 


\section{Benefits of Interconnection Process Improvements for Standard NEM}

Streamlining and automating the interconnection process for SNEM systems (up to $30 \mathrm{~kW}$ ) has yielded numerous time- and cost-savings benefits to PG\&E and its customers. These benefits include the elimination of numerous paper-based forms in lieu of a faster online process, reduced staff time requirements for application in-take and approval, direct utility cost savings, and improved customer satisfaction.

\subsection{Time-Savings Benefits}

A key indicator of the EGI team's success is the time duration required for application processing and approval relative to the number of applications received. In cases of application backlog, utility processing times are likely to increase on account of utility staff and systems becoming overwhelmed with greater application volume. This backlog can often have a "snow ball" effect in which it becomes increasingly more difficult for the utility to keep pace with new requests. Yet, as Figure 3 illustrates, PG\&E has actually been able to reduce application review and approval time despite rapid increases in the number of applications received. As shown in Figure 3, during 2012 — when application rates increased from roughly 1,000 to 2,000 per month - the process started to exceed PG\&E's internal time frame target and began to approach the regulatory limit. The median application cycle time ${ }^{2}$ increased about $3 x$. In response to this uptick, PG\&E began its initial effort to simplify the process. This first wave of process simiplification enabled cycle times to fall from a peak of about 20 days during the fall of 2012 to the 7-10 day range in early 2013. Then, in mid-2013, as application rates rose from roughly 2,000 to 3,000 per month, the cycle time again spiked. In late-summer 2013, with the median cycle time approaching 20 days, PG\&E implemented a second round of process simplifications, along with staffing improvements and increased process automation, bringing cycle times down to below 5 days by December 2013. These improvements enabled PG\&E to keep cycle times under control through 2014 as application rates increased from roughly 3,000 to 5,000 per month. Based on the quartiles identified in Figure 4, PG\&E's $50^{\text {th }}$ and $90^{\text {th }}$ percentile range for cycle time have both approached 3 days in 2015. As PG\&E continues to focus on process simplification, it is apparent that in the very near future $95 \%$ of all applications received will be processed within 3 days, as depicted by the orange 95th percentile line in Figure 4. The realized improvements in application review and approval time enables PV developers to complete projects efficiently and meet important financial and incentive deadlines. As PV companies realize faster project development rates and throughput, PG\&E customer relations, in turn, benefit immensely as the overall process burden of project completion decreases. Furthermore, shorter cycle times help ensure PG\&E's compliance with the CPUC interconnection time-frame mandate, i.e., that investor-owned utilities complete SNEM application reviews and PTO processes in 30 business days from submittal of a complete Interconnection Request, a signed Interconnection Agreement, and evidence of the final electric inspection certificate from the authority having jurisdiction.

\footnotetext{
${ }^{2}$ For the purposes of this case study, "cycle time" is measured as the number of business days from the date an application is deemed complete by the utility to the date the utility issues final permission to operate.
} 


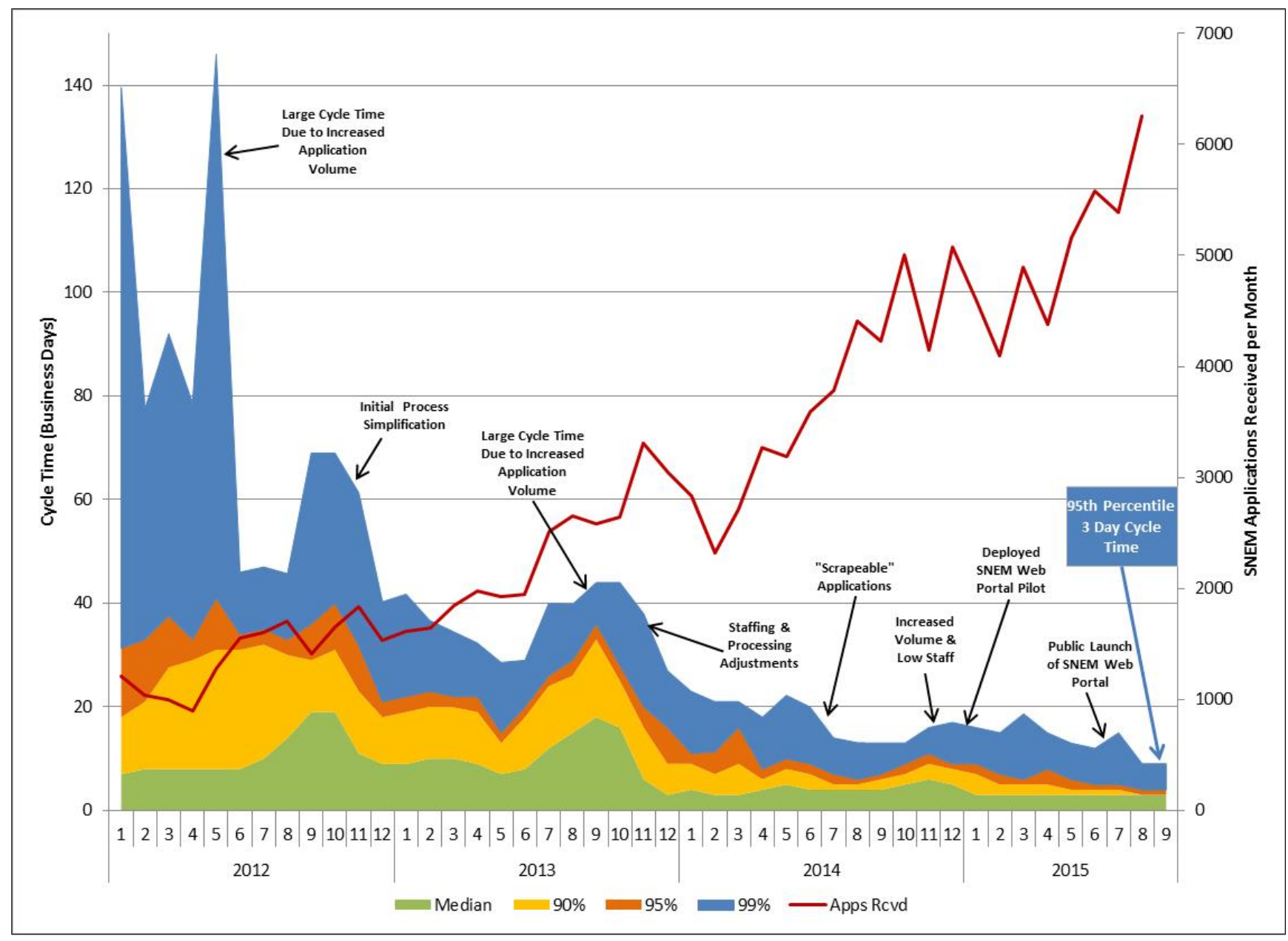

Figure 4: PG\&E Standard NEM Cycle Time Quartiles

\subsection{Cost-Savings Benefits}

Time savings and increased business process efficiency translate to direct cost savings for the utility. Table 1 depicts the fourth quarter (Q4) average processing cost per SNEM application received. From Q4 2012 to Q4 2014, PG\&E's average per unit processing cost decreased 68\%from $\$ 195$ to $\$ 62$. For 2015, PG\&E's average per unit processing cost is targeting \$40. PG\&E's projected cost decrease from 2012 to 2015 translates to a total cost savings of $\$ 25.8$ million over 4 years (Figure 5). With a total upfront investment of \$1.5 million for SNEM enterprise software, process streamlining, and other back-end information technology systems integration, PG\&E has recuperated their original investment 16 times over, as measured by direct processing cost savings. In addition to quantifiable, direct, cost saving, PG\&E's improvement measures also yielded improved customer relations and compliance with regulatory requirements. 
Table 1: PG\&E Average Processing Cost per Standard NEM Interconnection Application

\begin{tabular}{|c|c|}
\hline Year & $\begin{array}{c}\text { Q4 Avg. Unit Cost** } \\
(\mathbf{S})\end{array}$ \\
\hline $\mathbf{2 0 1 2}$ & 195 \\
\hline $\mathbf{2 0 1 3}$ & 92 \\
\hline $\mathbf{2 0 1 4}$ & 62 \\
\hline $\mathbf{2 0 1 5}$ & $39 *$ \\
\hline
\end{tabular}

*Targeted Q4 2015 Average Unit Cost (\$)

**Unit cost represents the administrative cost to process an application. This cost excludes installation, commission, or inspection of the meter; required interconnection facility; or distribution upgrades or costs associated to set up billing. August 2015 average unit cost is at $\$ 42$

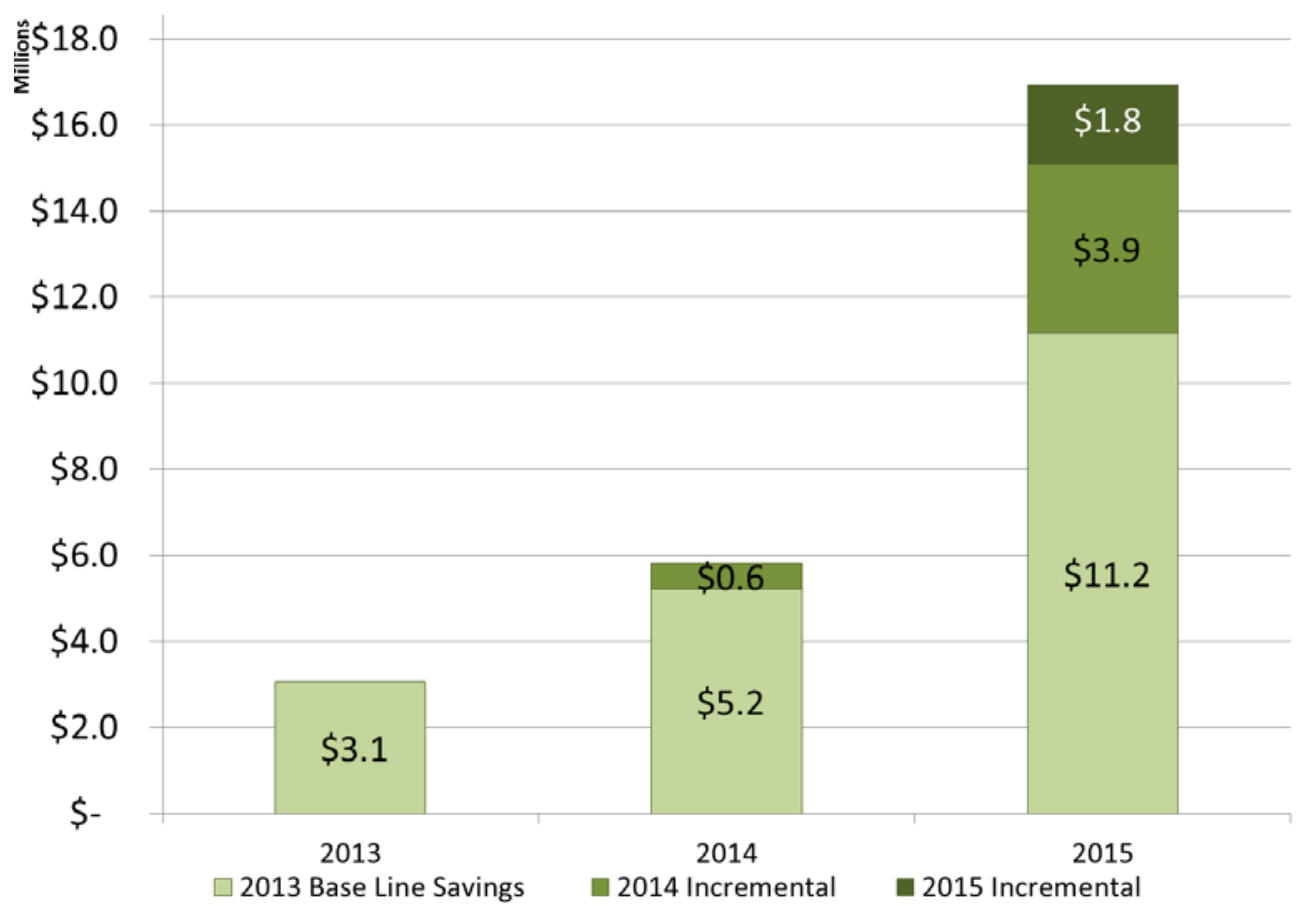

Figure 5: Annual Cost Savings from Standard NEM Process Improvements 


\section{Future and Planned Improvements}

\subsection{Expanded NEM and Other Rule 21}

After the successful implementation of process improvements for wholesale and standard NEM PV, moving forward, EGI has plans to improve the interconnection process for expanded NEM projects, as well. Expanded NEM projects range from $50 \mathrm{~kW}$ to $1 \mathrm{MW}$, and interconnection applications tend to require more inputs than standard NEM. As of the writing of this case study, PG\&E is actively working toward the launch an online tool for expanded NEM applications, called the Application Configuration and Eligibility Interconnection Tool (ACE-IT). This new online tool will incorporate many of the lessons learned from simplifying, streamlining, and automating the other interconnection streams, i.e., to automate application configuration and determine interconnection eligibility for expanded NEM projects.

Key features of this new tool include:

- Ability to automatically determine which tariff and interconnection program that a new application is eligible for, resulting in significant time savings for the customer and PG\&E.

- Capability to automatically direct customers only to the application sections that are required for the specific tariff that the proposed project is subject to, thereby avoiding customers filling out sections of applications that are not required.

- Simplified application completion and submission via an online web tool that is processed centrally, similar to NEM applications, and then linked to PG\&E's asset registry and billing system.

\subsection{All Interconnection Tracks}

Additional, planned improvements to PG\&E's interconnection process include moving toward an "exception-only process" for human engineering review. In this process, only the projects anticipated to have a negative grid impact are required to have a personal review and screening prior to PG\&E issuing an interconnection agreement. The EGI team is also working with permitting authorities having jurisdiction (AHJs) within PG\&E's territory to streamline final interconnection approval by having each AHJ automatically upload certifications of passed final building inspection to PG\&E's central interconnection database. Verification of passed final building inspection is required for final permission to operate from the utility; therefore, this enhanced coordination between the AHJ and PG\&E has the potential to significantly reduce the occurrence of PTO-related delays (Ardani et al. 2015, IREC 2013). These efforts are part of the EGI team's broader goal to increase overall interconnection process automation without compromising grid safety and reliability. In addition, PG\&E is transitioning away from its current system for grid visualization, PV RAM, to a more sophisticated GIS-based approach to maintain maps showing current PV penetration levels, in compliance with AB 327. This advancement will be especially helpful to project developers, enabling them to identify good project sites to target for PV interconnection, thereby reducing speculative interconnection applications. The EGI team also integrated CPUC- and CSI-mandated data collection into application forms and processes and is developing the ability to integrate storage and NEM Aggregation requirements into ACE-IT. 


\section{Key Lessons Learned}

As PV volumes continue to rise, other utilities, such as San Diego Gas and Electric and ConEdison, have streamlined and improved the interconnection process within their territories, as well. Like PG\&E, these and other utilities recognize the opportunities for cost and time savings and increased ease of regulatory compliance and tracking. The factors influencing investment decisions will differ across utilities, but in the case of PG\&E, it became clear that investing in back-end data systems integration and online application functionality would enhance the company's bottom line.

The PG\&E EGI team's overall strategy to improve the interconnection process consisted of three primary phases: 1) review and simplify requirements, 2) streamline the process by eliminating duplicative efforts and increasing coordination among departments, and 3) automate application throughput by eliminating human intervention. This three-phase strategy has yielded multiple time- and cost-savings benefits, has improved customer relations, and has eased the projecttracking requirements for regulatory compliance.

Multiple factors have helped the EGI team implement this strategy effectively. The first is that the EGI staff now manages all interconnections centrally. This is in contrast to the situation at many utilities, where there are separate departments that handle standard NEM, expanded NEM, and exporting PV applications. Centralizing the team and its operations has greatly increased the effectiveness of process reforms. Second, recognizing that the solar market is dynamic and evolving rapidly, the EGI team is continually adjusting processes as tariffs and regulatory requirements change. A high level of flexibility, both in terms of staffing and processes, as well as responsiveness to PV market growth has been critical to the EGI team's success. Third, the EGI team prioritized overcoming internal inertia and resistance to change by consistently working toward a series of integrated process improvements that span multiple layers of PG\&E management.

Adopting the technology needed to move from a paper-based system to an online process, coupled with back-end integration of multiple, separate informational repositories are foundational to PG\&E's interconnection process improvements. The exact impetus and implementation methods may vary by interconnection track and project scale, with wholesale improvements driven by regulatory compliance and standard NEM motivated more by rising volume. However, PG\&E's EGI team has demonstrated the myriad benefits of process improvements to both the utility and its customers. 


\section{References}

Ardani, K.; Davidson, C.; Margolis, R.; Nobler, E; (2015). A State-Level Comparison of Processes and Timelines for Distributed Photovoltaic Interconnection in the United States. NREL/TP-7A40-63556. Golden, CO: National Renewable Energy Laboratory. http://www.nrel.gov/docs/fy15osti/63556.pdf

IREC (Interstate Renewable Energy Council) (2013). Minimizing Overlap in PV System Approval Processes. Latham, NY: Interstate Renewable Energy Council.

Pacific Gas and Electric (2015). What is Electric Rule 21?

(www.pge.com/en/b2b/energytransmissionstorage/egi/grid/rule21/whatisrule21/index.page), accessed September 18, 2015.

Woerner, B. Innovation in the Interconnection Application Process. Webinar for NREL and SEPA's Distributed Generation Interconnection Collaborative. http://www.nrel.gov/tech deployment/pdfs/2014-04-02 innovation-in-theinterconnection-application-process.pdf 